\title{
NUMERICAL DESIGN MODEL OF FURNACE REACTOR FOR ETHANE CRACKING
}

\author{
Wordu A. A ${ }^{1}$, Akinola B ${ }^{2}$ \\ ${ }^{I}$ Department of Chemical/Petrochemical Engineering, University of Science and Technology, Nkpolu, Porthacourt, \\ Rivers State, Nigeria \\ ${ }^{2}$ Department of Chemical/Petrochemical Engineering, University of Science and Technology, Nkpolu, Porthacourt, \\ Rivers State, Nigeria
}

\begin{abstract}
Appropriate design models for typical furnace reactor for cracking of 100\% ethane feed has been developed. The research considers the radiation, convective, pressure drop effect and composite heat balance on the convective and radiation zones of the reactor operations. Principles of material and energy balances and pressure effects from the flow of feed material from the convective section to the radiation zone were incorporated into lumped-design model equations. The models were resolved applying numerical ode 45 to generate the profiles on conversion along the length of reactor, pressure drop effects and energy balance which were compared with plant data of Indorama Eleme petrochemicals complex to validate the dynamics in the reactor in figures 1,2,3, 4,5,6,7, and 8.The pressure effects profile of the reactor operation at steady states showed a quasi-flat shape at $30-45 \%$ conversion to constant pressure drop as depletion process progressed to 65\% upwards.
\end{abstract}

Keywords: Furnace Reactor, Radiation-Convection Sections, Cracking, Heat Balance Radiation-Convection, Design Model, Numerical.

$* * *$

\section{INTRODUCTION}

In Petrochemical industry, furnace reactor is the fundamental equipment for the cracking of ethane to yield ethylene. Ethylene production is one of the largest sectors and is the building blocks in manufacturing of petrochemicals. Notably among the olefins produced is ethylene whose worldwide production in 2012 (109 million tons in 2008) exceeds that of any other organic compound. Ethylene can also be synthesized by dehydrogenation of ethane. It is worthy to note that the dehydrogenation processes of ethane are expected to play a large role in the future production of ethylene since ethane is an abundant component in natural gas which is an alternate resource to traditional petroleum [3]. The furnace reactor consists of long coiled radiant tubes placed vertically inside a rectangular gas-fired furnace. The tubes are hung vertically to allow for expansion and to avoid sagging, consequently lengthening tube life. The furnace reactor system consists of the convection and radiation zones. The feedstock which is usually light hydrocarbons like ethane, ethane-propane mixtures or naphtha first enters the convection zone where it is pre-heated to about $500-800^{\circ} \mathrm{c}$ and any liquid vaporized before it enters the radiation zone where pyrolytic reactions takes place, inducing numerous free radical reactions. The products from the reactor are immediately quenched to stop these reactions. First, pyrolysis of ethane gives rise to some carbon (coke) formation. This coke deposition increases pressure drop and inhibits heat transfer up to a point where stops for mechanical cleaning are mandatory.

Furthermore, the energy change associated with the process is endothermic and consequently, requires huge energy. However, once started the energy efficiency is high as heat energy recovered from the cracked gas is used to make high pressure stream. This steam is in turn used to drive the turbines for compressing the cracked gas, propylene refrigeration compressor and the ethylene refrigeration compressor [8].

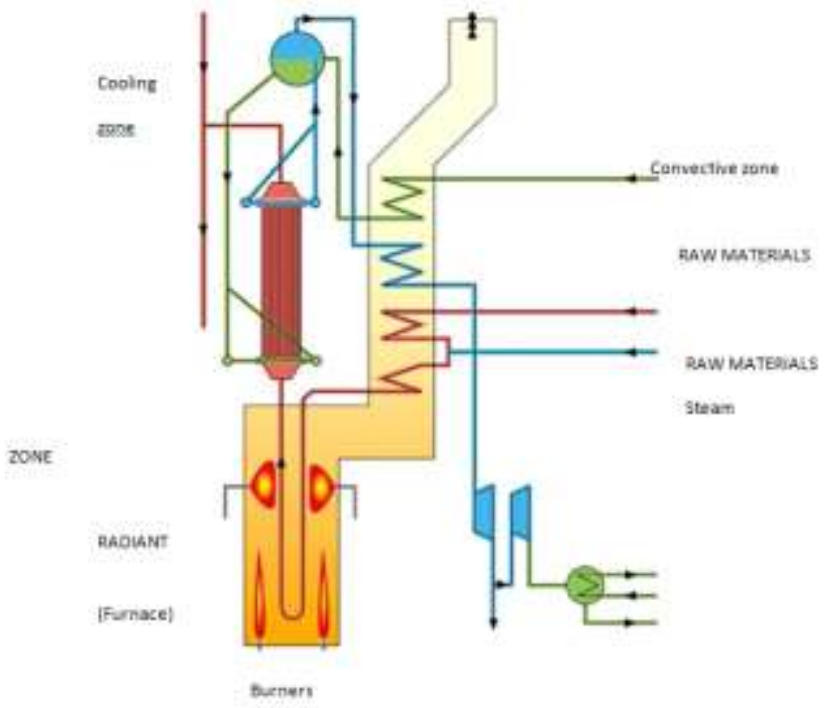

Fig 1: Schematics of atypical ethane furnace reactor

\subsection{Process Concept of Furnace Reactor}

The reactor is identified to comprise of two major sections of cracking reactions, radiation and convective zones. The kinetics and convective forces of ethane cracking process is essentially coupled in the numerical computer model for investigative study. Literature have shown that research 
have been carried out on the radiation section [1], but did not consider convective section forces on the cracking process and the pressure drop along the reactor. The observed gap in the previous research forms the main framework of the present research.

\section{MATERIALS AND METHOD}

The furnace reactor is modeled as a tubular reactor. Design equations for predicting material and energy interchange in the reaction zone of the reactor as well as equation accounting for pressure drop along the reactor length were developed. Radiation and convective heat transfer equations were established to account for temperature effects in the convective zone of the reactor and then coupled with the overall energy balance of the reactor system.

\subsection{Process Chemistry}

Pyrolysis of ethane is represented essentially by the irreversible first order chemical reaction equation in the temperature range of 900 to $1200 \mathrm{~K}$.

The stoichiometric balanced equation for ethane cracking process in furnace reactor is kinetically stated as [7]

$$
\mathrm{C}_{2} H_{6(g)} \rightarrow \mathrm{C}_{2} H_{4(g)}+H_{2(g)}
$$

A pure ethane is fed at known inlet temperature and pressure to a steel tube contained in an ethane pyrolysis furnace. Heat is supplied by the furnace to the reactor. At temperatures of about $980-1200^{\circ} \mathrm{C}, \mathrm{C}-\mathrm{H}$ bonds of ethane molecules dissociates such that ethylene and hydrogen are produced as major products. Conversion of ethane to ethylene can be as high as $65-70 \%$. Thermodynamic properties such as standard heat of formation $\left(\Delta H^{0}{ }_{298}\right)$, Specific heat capacity $(\mathrm{Cp})$ and related kinetic data for chemical species associated with the reaction equation (1) above is as shown in table (1) below [6]

Table1. Physical Properties and data for ethane pyrolysis reaction

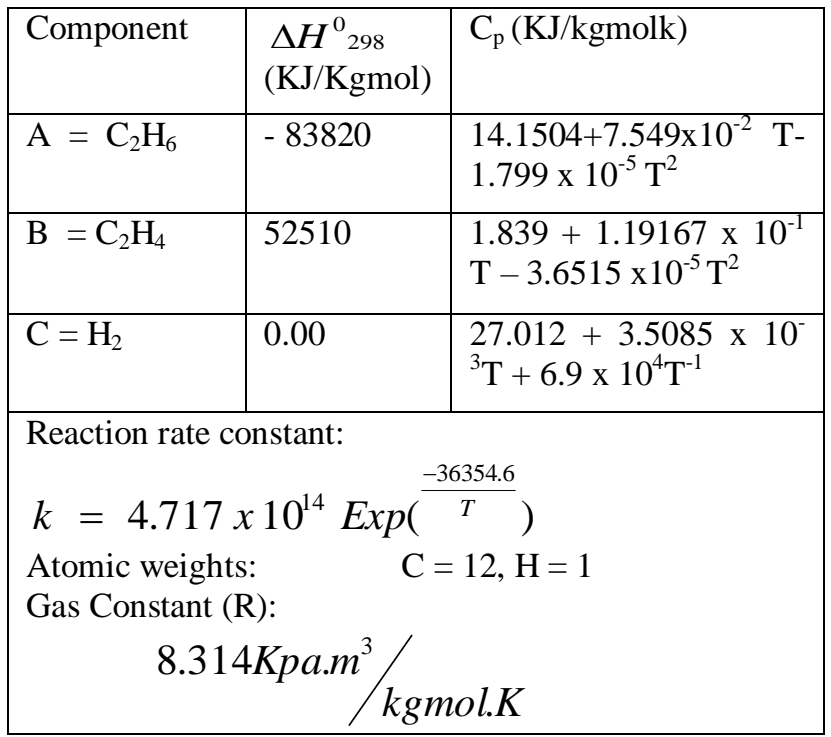

\subsection{Material Balance}

The furnace reactor is modeled as a plug flow reactor. The approach involves establishing the steady state material balance over a differential volume element $\left(\mathrm{dV}_{\mathrm{R}}\right)$ of reactor length $(\mathrm{dz})$, as shown in figure (1) below. Basis is a mole of ethane.

\begin{tabular}{rl|l|l}
\hline$F_{A O} \rightarrow F_{A} \rightarrow$ & $d V_{R}$ & $\rightarrow F_{A}+d F_{A}$ \\
\hline & $\rightarrow$ & $\mathrm{dz}_{\mathrm{z}}$ & $\leftarrow$
\end{tabular}

Fig 2: Differential Element Of Tubular Reactor

Taking a balance for 1 mole of fresh feed of ethane A over the differential reactor volume $\left(\mathrm{dv}_{\mathrm{R}}\right)$; rate of inflow of feed into differential volume element $\mathrm{F}_{\mathrm{A}}$ equal to rate of outflow of feed from differential volume element $F_{A}+d F_{A}$ minus rate of depletion of feed due to chemical reaction within differential volume element $\left(-r_{A}\right) d v_{R}$ and rate of accumulation of feed within volume element at steady state process gives equation (2),

$$
\begin{aligned}
& F_{A}=\left(F_{A}+d F_{A}\right)+-r_{A} d v_{R}+0 \\
& \therefore F_{A}+r_{A} d v_{R}=F_{A}+d F_{A} \\
& \therefore \quad r_{A} d v_{R}=d F_{A}
\end{aligned}
$$

The differential reactor volume element $\left(\mathrm{dv}_{\mathrm{R}}\right)$ is related to the differential reactor length by;

$\mathrm{dv}_{\mathrm{R}}=\mathrm{Adz}$

By substituting equation (4) into (3) and rearranging, we obtain;

$$
\begin{array}{ll}
\therefore & r_{A}=\frac{d F_{A}}{d v_{R}}=\frac{d\left[F_{A O}\left(1-\alpha_{A}\right)\right]}{A d z} \\
\therefore & r_{A}=-\frac{F_{A 0}}{A d z} d \alpha_{A}
\end{array}
$$

For a first-order irreversible reaction, the kinetic rate equation is given mathematically;

$$
-r_{A}=K_{1} C_{A}
$$

At low pressure $(\mathrm{P}<5$ bar $)$ of the reacting gas mixture, the gas law

$$
\begin{aligned}
& P_{A} V_{A}=n_{A} R T_{R} \\
& \frac{n_{A}}{V_{R}}=C_{A}=\frac{P_{A}}{R T_{R}}
\end{aligned}
$$




$$
\therefore \quad C_{A}=\frac{P_{A}}{R T_{R}}
$$

From Daltons’ Law;

$$
P_{A}=y_{A} P_{\text {TOt }}
$$

By substituting equation (9) into (8) we obtain;

$\mathrm{C}_{\mathrm{A}}=\frac{y_{A} P_{T o t .}}{R T_{R}}$

Substituting (10) into (6) we obtain the rate equation

$r_{A}=-K \frac{y_{A} P_{T o t}}{R T_{R}}$

Hence, determine the mole fraction of ethane $\left(\mathrm{y}_{\mathrm{A}}\right)$, mole balance of the reacting species with respect to differential volume element figure 1 is shown in table 2 below;

Table 3. Mole balance for the reacting species

\begin{tabular}{|l|l|l|}
\hline Component & $\begin{array}{l}\text { Inlet molar } \\
\text { flow rate }\end{array}$ & $\begin{array}{l}\text { Outlet molar flow rate } \\
\text { at conversion } \mathrm{x}\end{array}$ \\
\hline $\mathrm{A}=\mathrm{C}_{2} \mathrm{H}_{6}$ & $\mathrm{~F}_{\mathrm{AO}}$ & $\mathrm{F}_{\mathrm{AO}}\left(1-\alpha_{A}\right)$ \\
\hline $\mathrm{B}=\mathrm{C}_{2} \mathrm{H}_{4}$ & 0 & $\mathrm{~F}_{\mathrm{AO}} \alpha_{A}$ \\
\hline $\mathrm{C}=\mathrm{H}_{2}$ & 0 & $\mathrm{~F}_{\mathrm{AO}} \alpha_{A}$ \\
\hline TOTAL & $\mathrm{F}_{\mathrm{TO}}=\mathrm{F}_{\mathrm{AO}}$ & $\begin{array}{l}\mathrm{F}_{\mathrm{T}}=\mathrm{F}_{\mathrm{AO}}+\mathrm{F}_{\mathrm{AO}} \alpha_{A}= \\
\mathrm{F}_{\mathrm{AO}}\left(1+\alpha_{A}\right)\end{array}$ \\
\hline
\end{tabular}

Hence, mole fraction of ethane $\left(\mathrm{y}_{\mathrm{A}}\right)$ is given by;

$$
y_{A}=\frac{\text { molar flow of ethane }}{\text { Total molar flow of gas }}
$$

$y_{A}=\frac{1-\alpha_{A}}{1+\alpha_{A}}$

By substituting equation (13) into (10), we have:

$$
r_{A}=-K\left(\frac{1-\alpha_{A}}{1+\alpha_{A}}\right) \frac{P_{T o t}}{R T_{R}}
$$

By equating (5) and (14) we obtain;

$$
r_{A}=-\frac{F_{A O}}{A} \frac{d_{X}}{d z}=-K\left(\frac{1-\alpha_{A}}{1+\alpha_{A}}\right) \frac{P_{T o t}}{R T_{R}}
$$

$$
\therefore \frac{d \alpha_{A}}{d z}=K\left(\frac{1-\alpha_{A}}{1+\alpha_{A}}\right) \frac{P_{T o t .}}{F_{A O} R T_{R}}
$$

Hence the conversion $\mathrm{X}_{\mathrm{A}}$ as a function of reactor length $\mathrm{z}$ is defined by the solution of the first order ordinary differential equation (15).

From the Arrhenius Equation;

$$
\mathrm{K}_{1}=\mathrm{A}_{1} \operatorname{Exp}\left(\frac{E}{R T_{R}}\right)
$$

and by using data from table (1) we have;

$$
K_{1}=4.717 \times 10^{14} \operatorname{Exp}\left(-\frac{363546}{T}\right)
$$

Substituting equation (17) into (15) yields;

$\frac{d \alpha_{A}}{d Z}=\left[\frac{4.717 \times 10^{14} A P_{\text {Tot. }}}{F_{A O} R}\right]\left[\frac{\operatorname{Exp}\left(-\frac{36354.6}{T_{R}}\right)}{T_{R}}\right]\left(\frac{1-\alpha_{A}}{1+\alpha_{A}}\right)$

For a given tube internal diameter, reactor pressure, and inlet ethane flow rate the term $\frac{4.717 \times 10^{14} A P_{T o t .}}{F_{A O} R}$ is

constant and the other term

$$
\frac{\operatorname{Exp}\left(-\frac{36354.6}{T_{R}}\right)}{T_{R}}
$$

dependent on temperature.

\section{ENERGY BALANCE}

The energy balance over the differential volume $\left(\mathrm{dv}_{\mathrm{R}}\right)$ element accounts for heat of reaction, heat transfer from furnace to the tube wall and sensible heat effects in the following gas stream.

The overall energy balance with respect to the differential volume element of the reactor is given by the fundamental equation below [5], [2]. 


$\left[\begin{array}{l}\text { Rate of Inflow of energy } \\ \text { Into differental } \\ \text { volume element }\end{array}\right]=\left[\begin{array}{l}\text { Rate of outflow of } \\ \text { energy from } \\ \text { differential volume } \\ \text { element }\end{array}\right]-\left[\begin{array}{l}\text { Rate of generationof } \\ \text { energydueto chemical reaction } \\ \text { within differential } \\ \text { Volume Element }\end{array}\right]+\left[\begin{array}{l}\text { of energy within } \\ \text { differential } \\ \text { Volume element }\end{array}\right]$

\section{Where;}

(i) Rate of inflow of energy into differential volume element is given by; $\mathrm{qdz}$

(ii). Rate of outflow of energy from differential volume element is given by;

$$
\Delta H_{T_{R}}=\left[F_{A} C_{P A}+F_{B} C_{P B}+F_{C} C_{P C}\right] d T_{R}
$$

Where:

\begin{tabular}{|l|l|}
\hline$A$ & $\mathrm{C}_{2} \mathrm{H}_{6}$ \\
\hline$B$ & $\mathrm{C}_{2} \mathrm{H}_{4}$ \\
\hline C & $\mathrm{H}_{2}$ \\
\hline
\end{tabular}

But,

$\mathrm{F}_{\mathrm{A}}=\mathrm{F}_{\mathrm{AO}}\left(1-\alpha_{\mathrm{A}}\right)$

$\mathrm{F}_{\mathrm{B}}=\mathrm{F}_{\mathrm{AO}} \alpha_{A}$

$\mathrm{F}_{\mathrm{C}}=\mathrm{F}_{\mathrm{AO}} \alpha_{\mathrm{A}}$

Substituting into equation (21) gives

$$
\begin{aligned}
& \Delta H_{T_{R}}=\left[F_{A 0}\left(1-\alpha_{A}\right) C_{P A}+F_{A O} \alpha_{A}\left(C_{P B}\right)+F_{A O} \alpha_{A} C_{P C}\right] d T_{R} \\
& \Delta H_{T_{R}}=\left[F_{A 0}\left(1-\alpha_{A}\right) C_{P A}+F_{A O} \alpha_{A}\left(C_{P B}+C_{P C}\right)\right] d T_{R} \\
& \therefore \Delta H_{T_{R}}=F_{A O}\left[\left(1-\alpha_{A}\right) C_{P A}+\alpha_{A}\left(C_{P B}+C_{P C}\right)\right] d T_{R}
\end{aligned}
$$

(iii) Rate of generation of energy due to chemical reaction within differential volume element is given by;

$$
F_{A O}\left(-\Delta H_{R}\right) d \alpha_{A}
$$

Substituting $\mathrm{F}_{\mathrm{A}}, \mathrm{F}_{\mathrm{B}}$, and $\mathrm{F}_{\mathrm{C}}$ values into (19), we obtain;

$$
F_{A 0} d \alpha_{A}\left(1-\Delta H_{R}\right)+q d Z=F_{A O}\left[\left(1-\alpha_{A}\right) C_{P A}+\alpha_{A}\left(C p_{B}+C_{P C}\right)\right] d T_{R}
$$

By dividing through equation (21) by $\mathrm{dz}$ and $\mathrm{F}_{\mathrm{AO}}$, then the change in temperature as a function of length is described by the first order ordinary differential equation.

$$
\frac{\left(-\Delta H_{R}\right) d \alpha_{A}}{d Z}+\left(\frac{q}{F_{A O}}\right)=\left[\left(1-\alpha_{A}\right) C_{P A}+\alpha_{A}\left(C_{P B}+C_{P C}\right)\right] \frac{d T_{R}}{d Z}
$$

Making $\frac{d T_{R}}{d Z}$ subject of equation;

$$
\frac{d T_{R}}{d Z}=\frac{\left[\frac{q}{F_{A O}}\right]+\frac{\left(-\Delta H_{R}\right) d \alpha_{A}}{d Z}}{\left(1-\alpha_{A}\right) C_{P A}+\alpha_{A}\left(C_{P B}+C_{P C}\right)}
$$

Where:

$\mathrm{q}=q_{c}+q_{R}$

The convective zone of the reactor preheats the feed to a temperature $T_{C}$. Heat from the flue gas of the furnace is transferred to the feed in two stages;

(1) Conductive heat transfer of heat from flue gas to internal surface of convective tube described by the equation;

$\frac{d q}{d A}=\frac{K}{\Delta d}\left[T_{F G}-T_{i}\right]$

(2) Convective heat transfer of heat from internal surface of tube to the feed gas described by the equation;

$\frac{d q}{d A}=h i\left[T_{C}-T_{i}\right]$

At steady state, heat transferred by conduction from flue gas to convective tube wall equals convective heat transferred from the tube wall to the flowing gas stream. Hence, by equating equation (28) to (29) we obtain;

$$
\frac{d q}{d A}=\frac{K}{\Delta d}\left[T_{F G}-T_{i}\right]=h i\left(T_{C}-T_{i}\right)
$$

From which we obtain; 
$\therefore T_{C}=\frac{K}{\Delta d}\left[T_{F G}-T_{i}\right]+T_{i}$

But, convective heat flux can be expressed by the equation;

$$
q_{c}=G C_{P A}\left(T_{C}-T_{i}\right)
$$

Substituting equation (31) into (32), we obtain (33) as;

$$
q_{c}=G C_{P A}\left(\frac{K}{h_{i} \Delta d}\right)\left(T_{F G}-T_{i}\right)
$$

For most applications, the heat flux $\left(\mathrm{q}_{\mathrm{R}}\right)$ to the tubes in the radiant section ranges between 20 to $40 \mathrm{KW} / \mathrm{M}^{2}$. For this work, a literature value of $20 \mathrm{KW} / \mathrm{M}^{2}$ is used. Hence, the total heat flux is given as;

$$
q=20+G C_{P A}\left(\frac{K}{h_{i} \Delta d}\right)\left(T_{F G}-T_{i}\right)
$$

Also, the heat capacity relationships in table 1 are applied directly in determining the heat of reaction $\left(-\Delta H_{R}\right)$ in equation (26) as shown in equation (35);

$$
\Delta H_{R}=\Delta H^{0}{ }_{298}+\int_{298}^{T}\left[C_{P B}+C_{P C}-C_{P A}\right] d T_{R}
$$

The heat of reaction at 298k $\left(\Delta H^{0}{ }_{298}\right)$ can be calculated from the heats of formation of Table 3.1 using the equation [6];

$$
\begin{aligned}
& \Delta H^{0}{ }_{298}=C_{P_{B}}^{0}+C_{P_{C}}^{0}-C_{P_{A}}^{0} \\
& =52510+0.0-(-83820) \\
& =52510+83820
\end{aligned}
$$

$$
\Delta H_{298}{ }^{0}=136,330 \mathrm{KJ} \text { per Kgmol. } \mathrm{K}
$$

Introducing the heat capacity relationships of table 1 and the calculated value for the heat of reaction at standard state $(298 \mathrm{~K})$ into equation (35) and integrating yields the heat of reaction $\left(\Delta H_{R}\right)$ at any reactor temperature $\mathrm{T}_{\mathrm{R}}(\mathrm{k})$ as shown;

$\Delta H_{R}=136,330+\left[24.701\left(T_{R}-298\right)+0.02384\left(T_{R}{ }^{2}-298\right)-6.177 \times 10^{-5}\left(T_{R}{ }^{3}-298^{3}\right)-\left(\frac{6.9 \times 10^{4}}{T_{R}-298}\right)\right]$

\subsection{Pressure Drop}

For flow of fluids in pipes, the pressure drop along the length of the pipe [5]

$\frac{d p_{T o t .}}{d Z}=-\frac{2 f G^{2}}{1000 \rho d}$

\subsection{Solution Technique}

Equations (19) and (26) are nonlinear equations developed and are subjected to iterative simultaneous numerical process to obtain the profiles as in figures 1, 2 and 3

\section{MODEL RESULTS}

Summary of simulation results obtained by linear interpolation is as shown in table1 below;
Table 1: Simulation Results

\begin{tabular}{|c|c|c|c|c|c|}
\hline $\mathrm{X}_{\mathrm{A}}$ & $\mathrm{d}(\mathrm{m})$ & $\mathrm{Z}(\mathrm{m})$ & $\mathrm{T}_{\mathrm{R}}(\mathrm{k})$ & $\begin{array}{c}\Delta \mathrm{p} \\
(\mathrm{Kpa})\end{array}$ & $\tau(\mathrm{S})$ \\
\hline 0.30 & 0.0508 & 133.1250 & 1100.00 & 0.5990 & 4.6945 \\
\hline 0.35 & 0.0635 & 136.8750 & 1185.00 & 0.6085 & 8.0480 \\
\hline 0.40 & 0.0762 & 140.6250 & 1460.00 & 0.6011 & 10.7430 \\
\hline 0.45 & 0.0890 & 141.2500 & 1460.10 & 0.6000 & 12.4190 \\
\hline 0.50 & 0.1016 & 145.0000 & 1460.50 & 0.5842 & 14.0950 \\
\hline 0.55 & 0.1270 & 148.7500 & 146.72 & 0.5789 & 15.7590 \\
\hline 0.60 & 0.1400 & 153.1250 & 1460.80 & 0.5730 & 17.4540 \\
\hline 0.65 & 0.1524 & 155.000 & 1461.00 & 0.5700 & 19.1780 \\
\hline
\end{tabular}

The simulation results is obtained by using Runge-Kutta numerical method for solving simultaneous differential equation on computer program mat lab ODE 45 for the three lumped equations (19), (26) and (38) generated from the design model. 


\section{DISCUSSION}

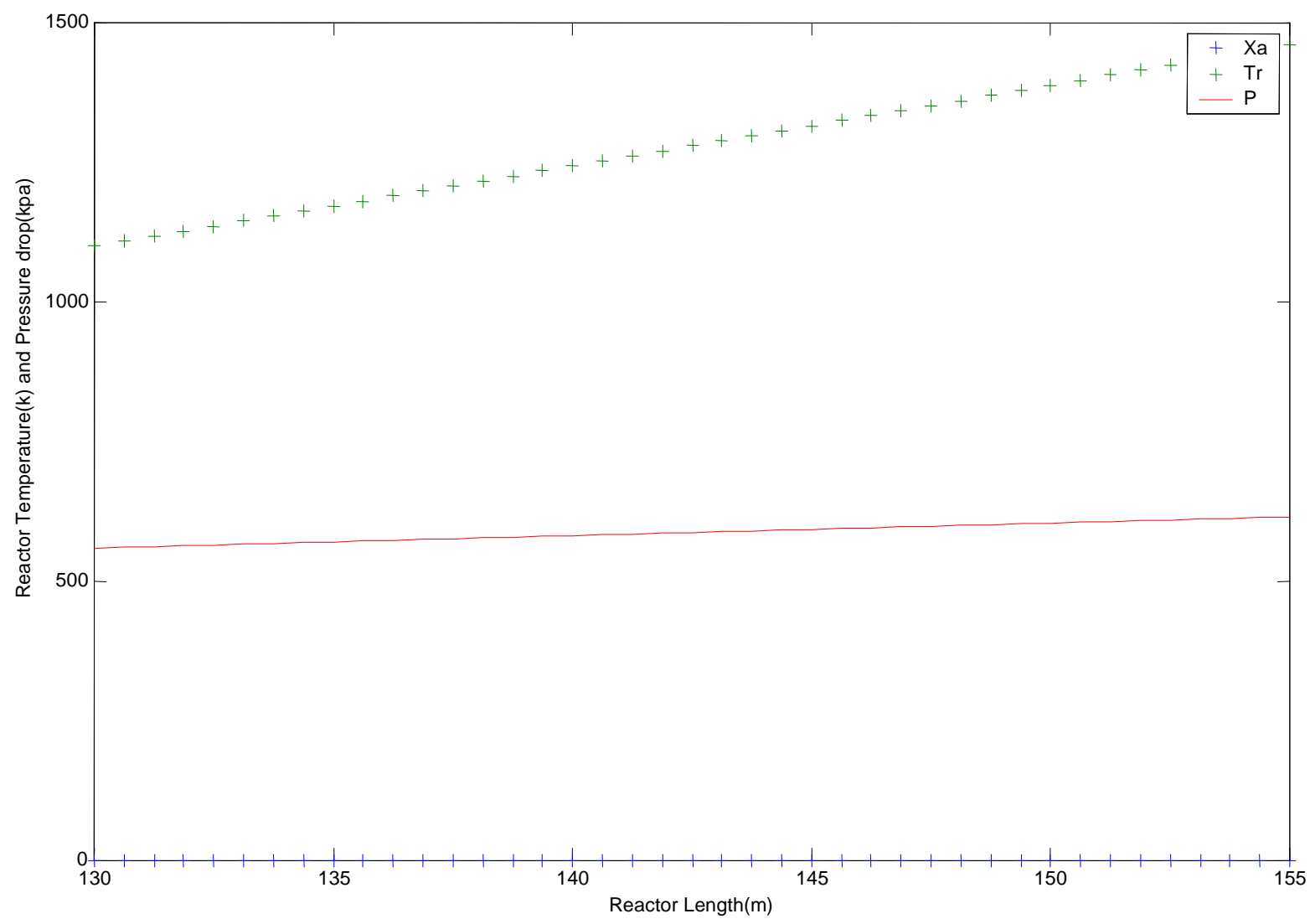

Fig 1: Plot of reactor Temperature and Pressure Drop for $\alpha_{A}=0.35, d=0.0635 m$ 


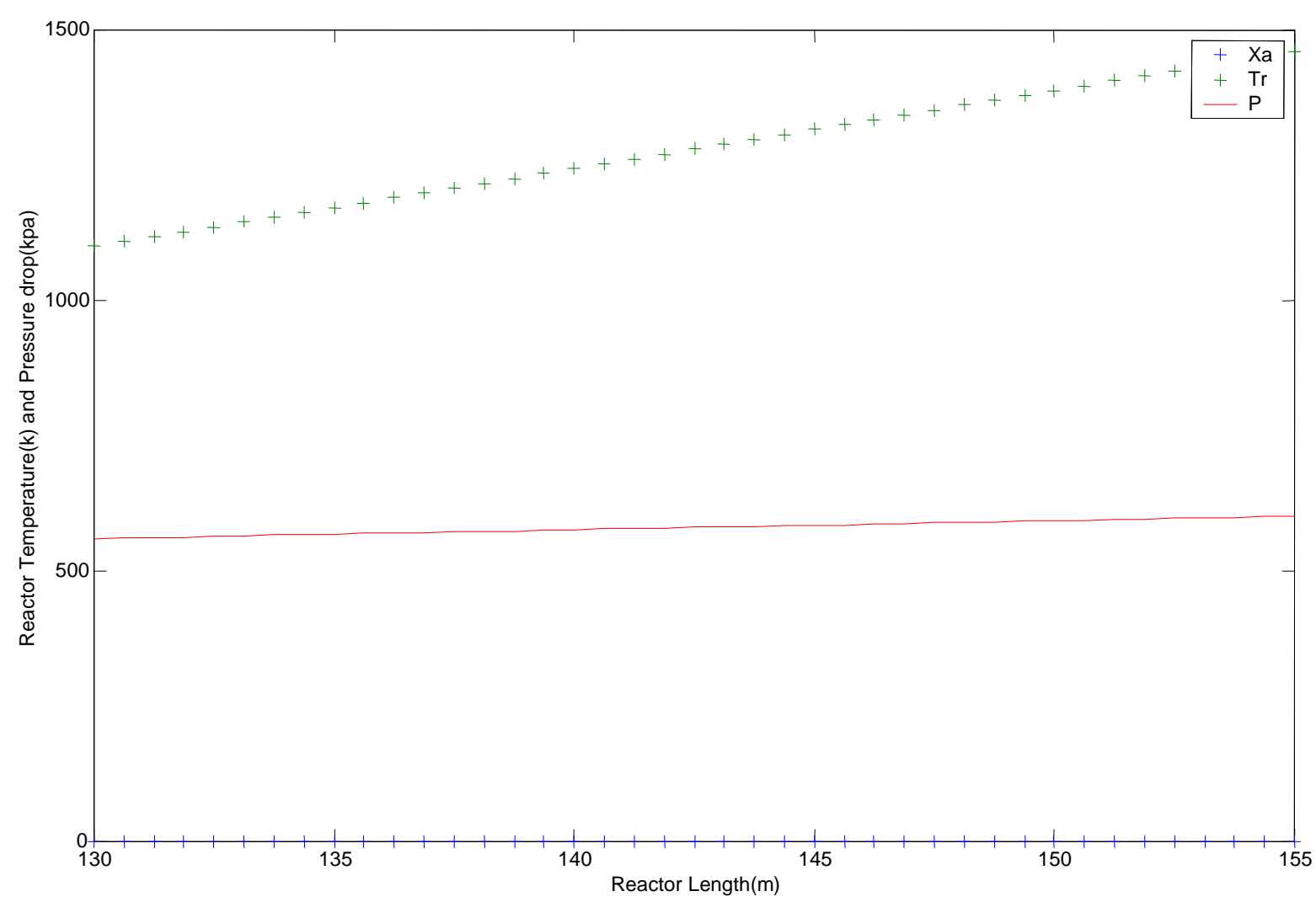

Fig 2: Plot of Reactor Temperature and Pressure drop against Reactor Length For $\alpha_{A}=0.40, d=0.0762 m$

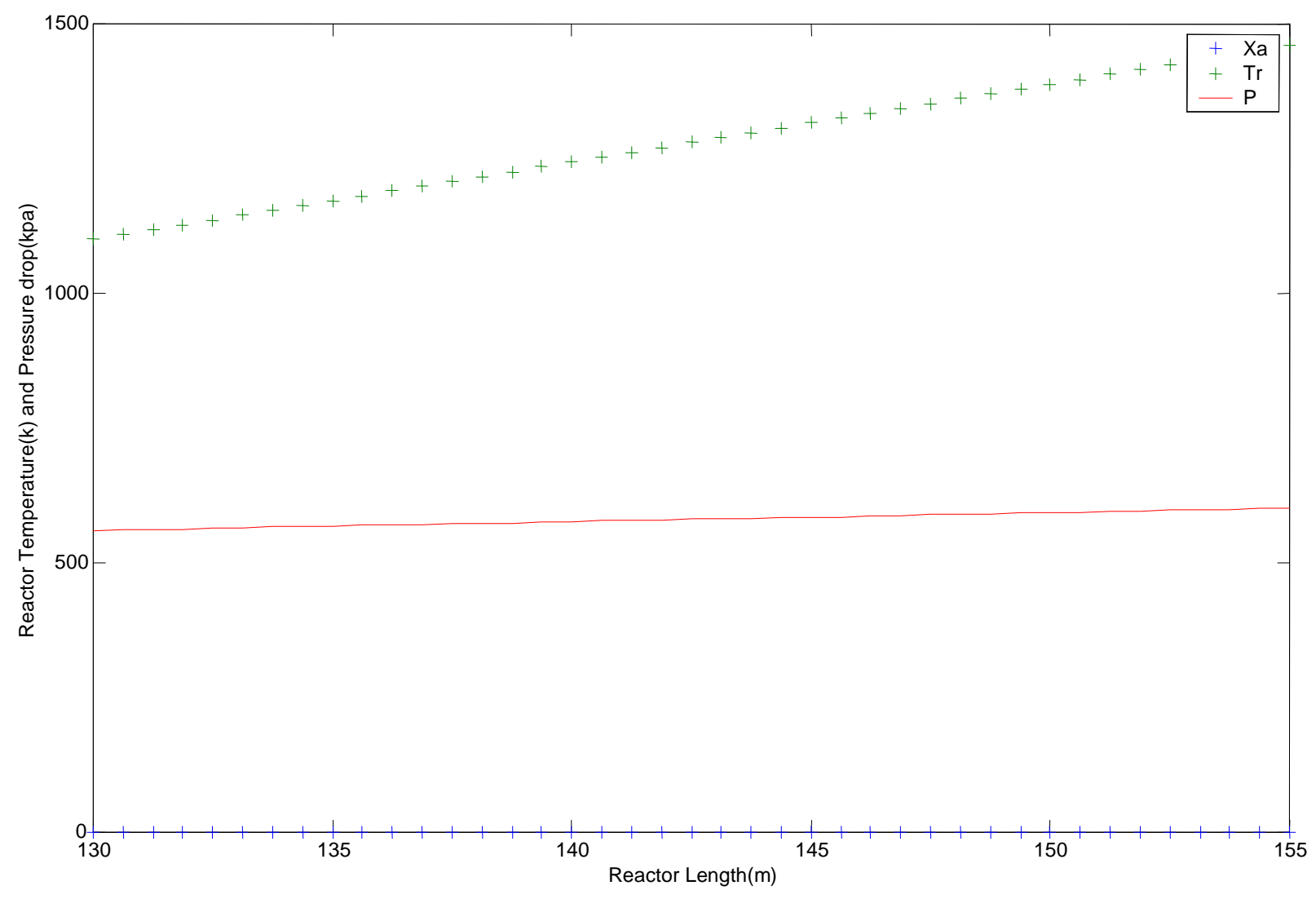

Fig 3: Plot of reactor temperature and pressure drop for $\alpha_{A}=0.4$ and $\mathrm{d}=0.0762 \mathrm{~m}$ 


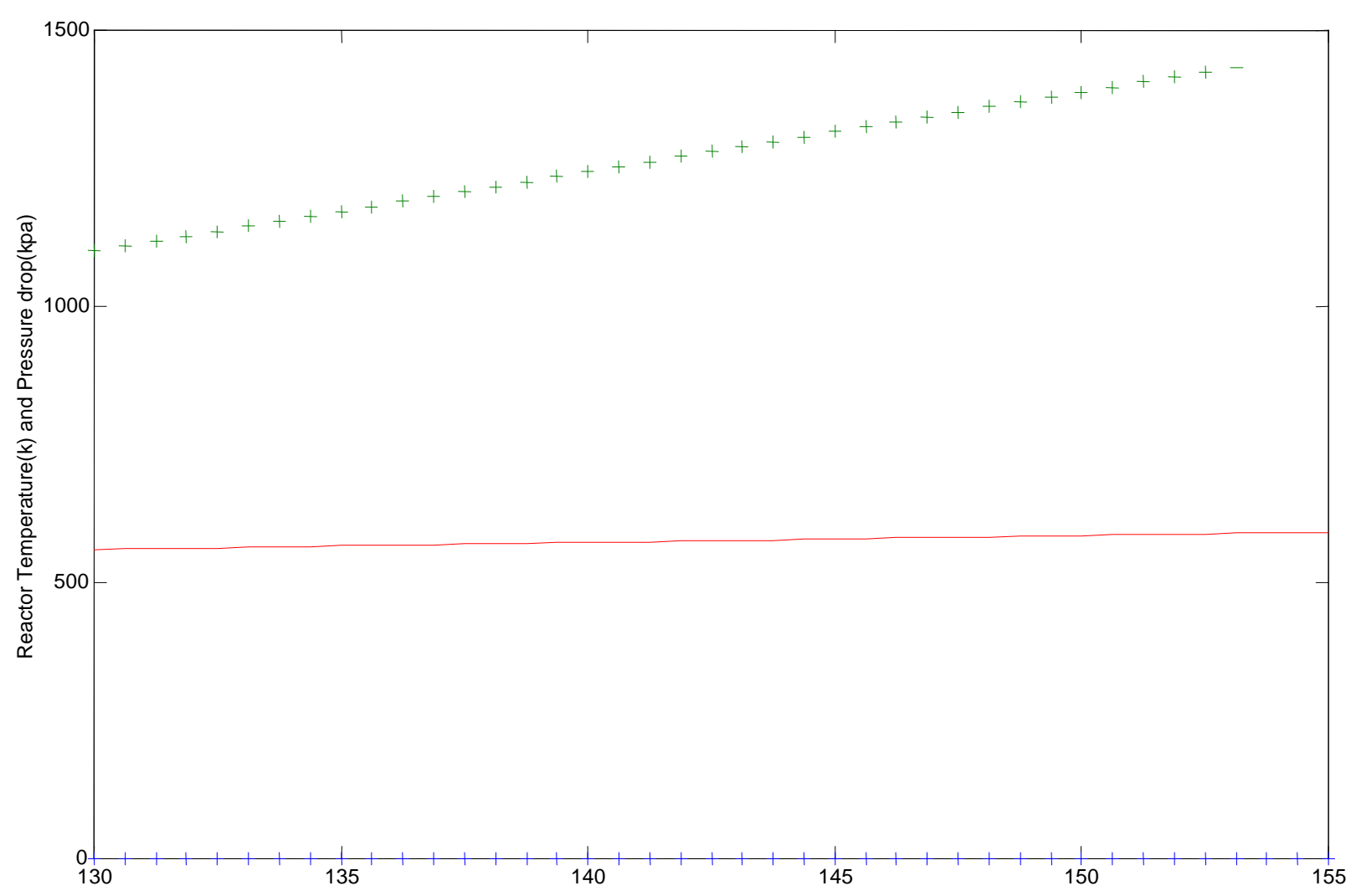

Fig 4: Plot of reactor temperature and pressure drop for $\alpha_{A}=0.45$ and $\mathrm{d}=0.0890 \mathrm{~m}$

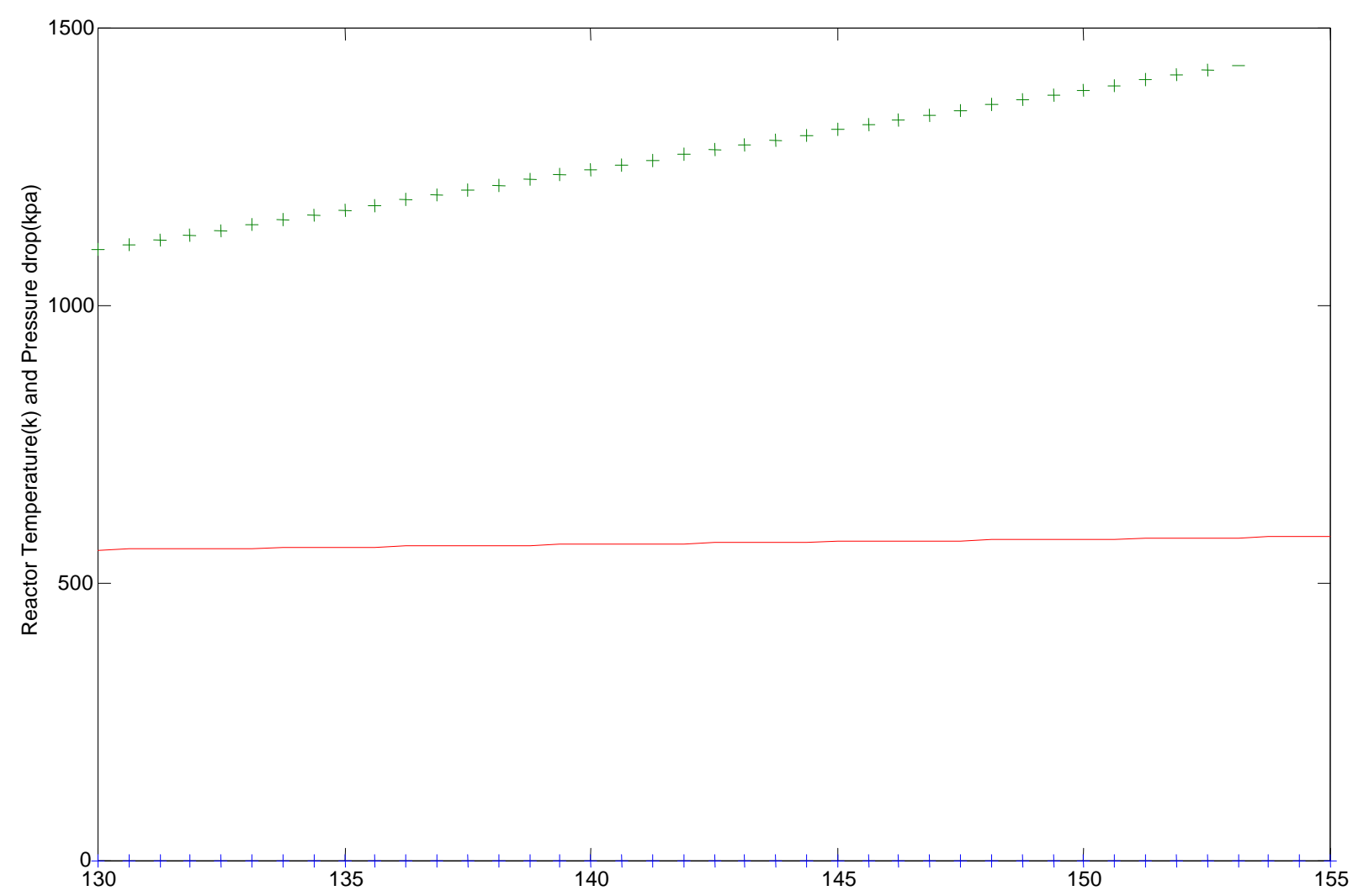

Fig 5: Graph of reactor temperature and pressure drop for $\alpha_{A}=0.5$ and d $=0.1016 \mathrm{~m}$ 


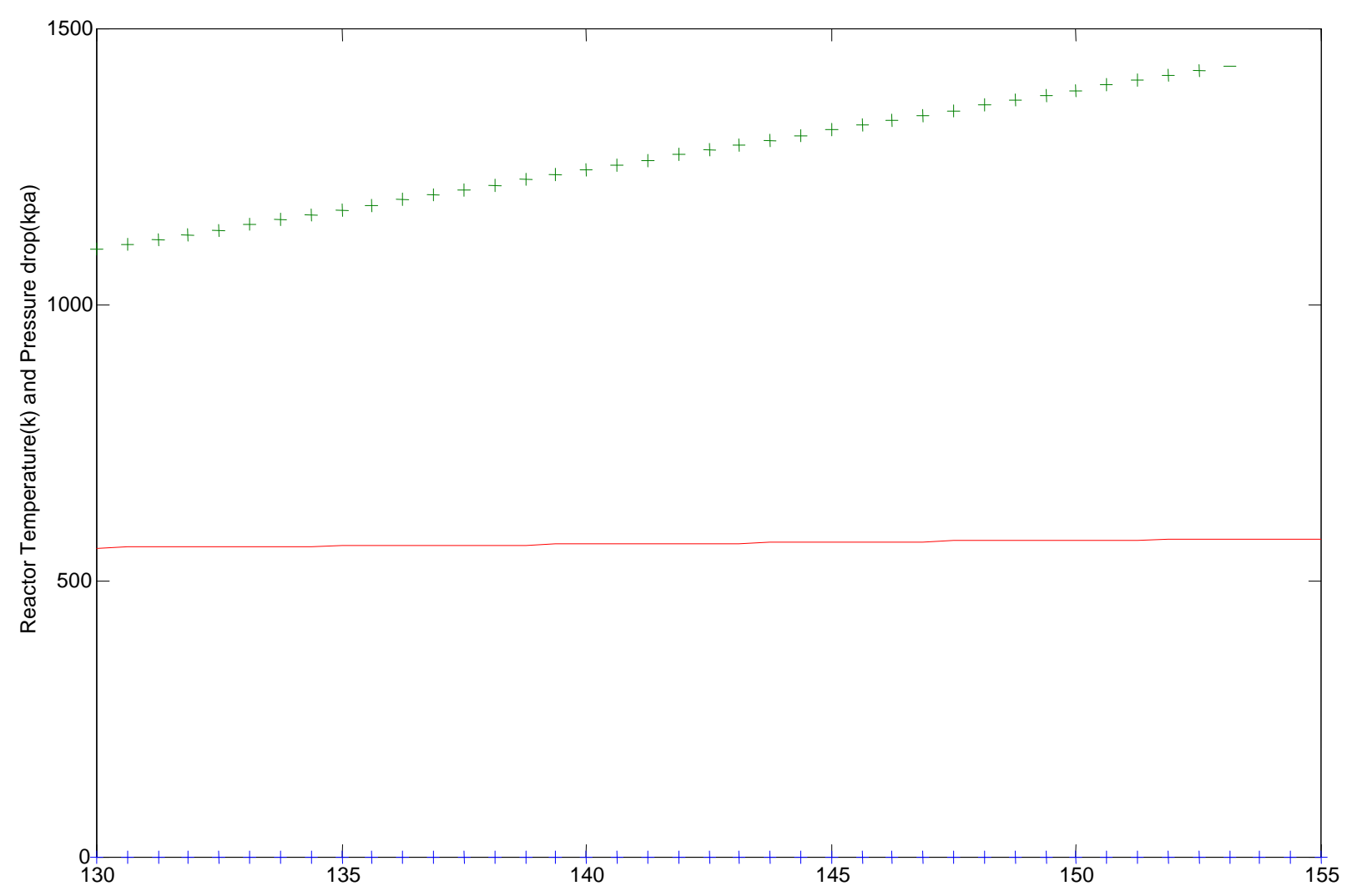

Fig 6: Graph of reactor temperature and pressure drop for $\alpha_{A}=0.55$ and d $=0.1270 \mathrm{~m}$

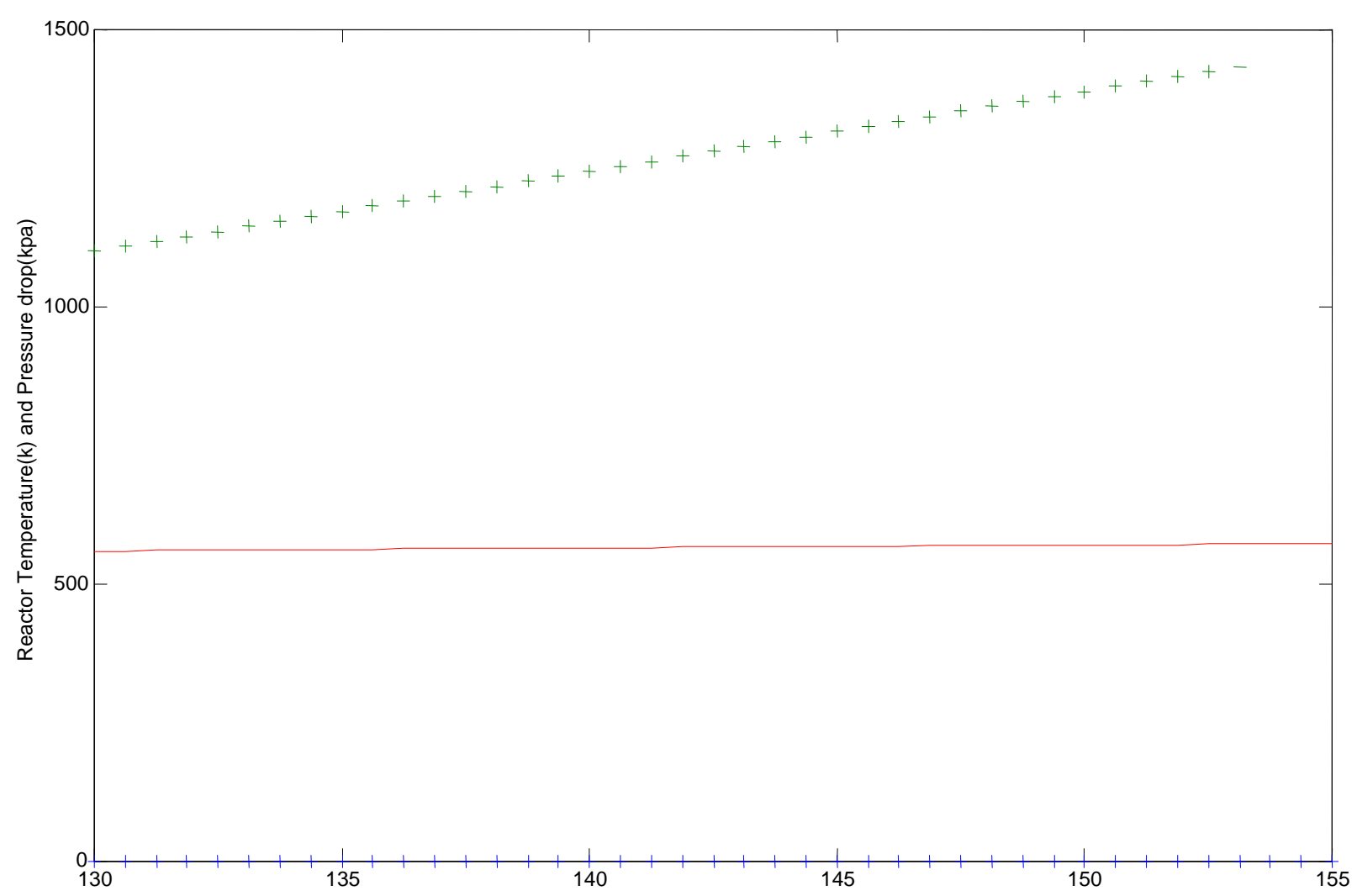

Fig 7: Graph of reactor temperature and pressure drop for $\alpha_{A}=0.6$ and $\mathrm{d}=0.14 \mathrm{~m}$ 


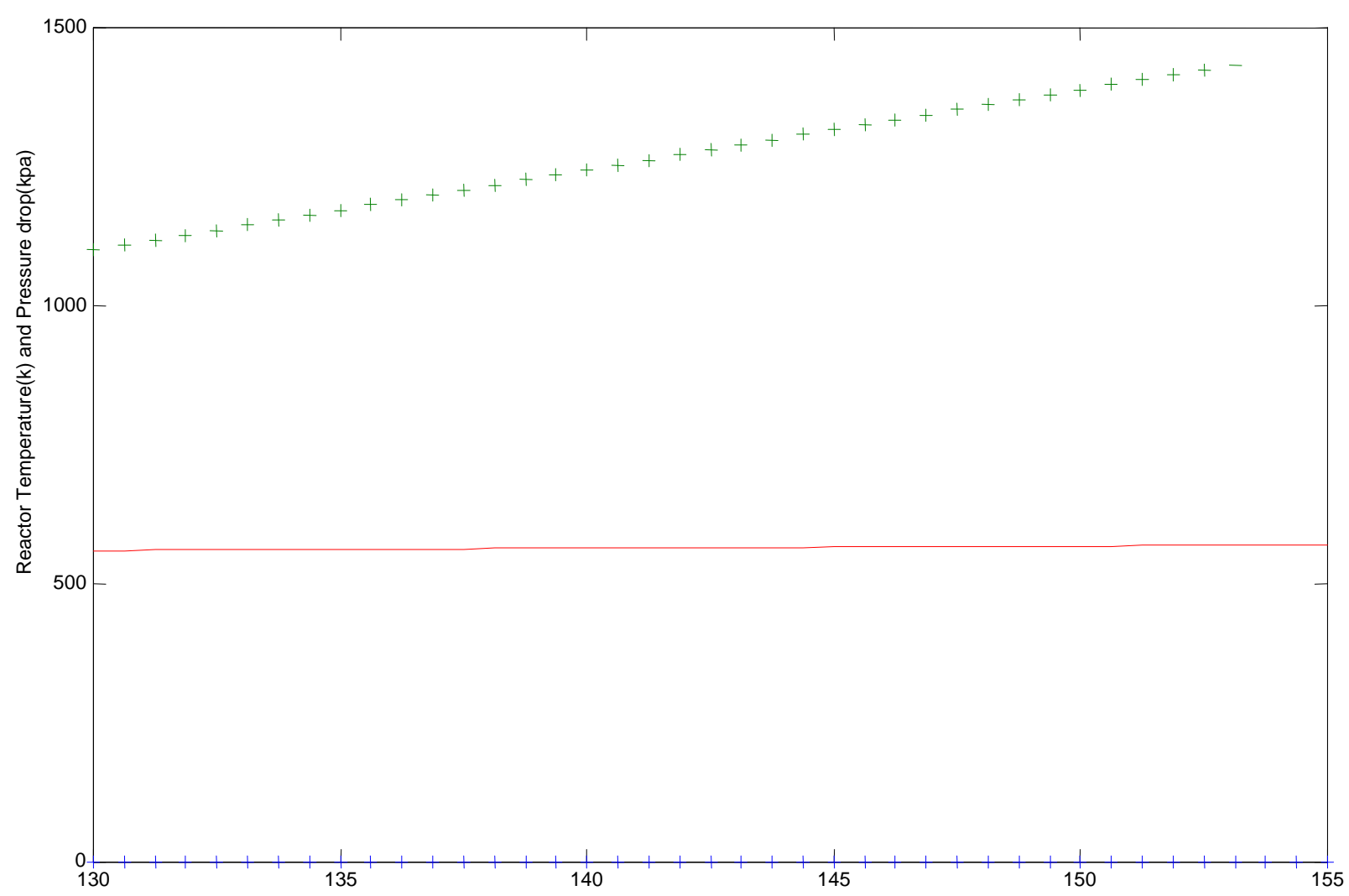

Fig 8: Graph of reactor temperature and pressure drop for $\alpha_{A}=0.65$ and d $=0.1524 \mathrm{~m}$

From the graphs on figures $1-8$, the reactor temperature increases along the length of the reactor from the convective zone to the radiation zone. This is expected because the heat flux to the radiation zone is greater than that of the convective zone as radiation zone is heated directly by the furnace and the convective zone is heated by the rising flue gas emanating from the furnace. The pressure drop increases steeply from the convective zone to the radiation zone at low conversion. At an optimum conversion of $65 \%$ as predicted by the model, the pressure drop maintains a constant flat shape along the length of the reactor and this is what is expected. For effective design, the pressure drop should remain constant as predicted by the model.

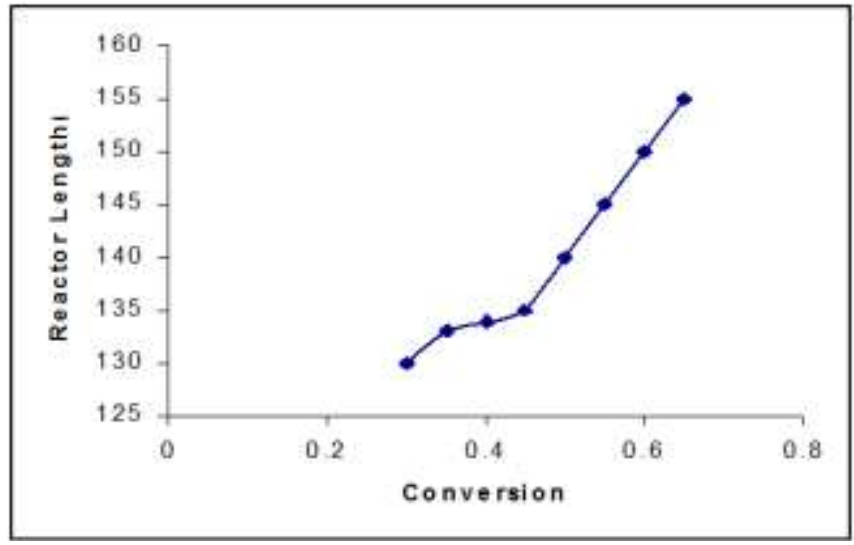

Figure 9 shows the conversion profile along the length of the reactor. There is only about $30 \%$ to $45 \%$ conversion of an ethane for the first 5 meters of the reaction zone. But as reactor temperature increases along the reactor length, the reaction conversion increases rapidly, and up to about 65$68 \%$ conversion for the remaining 20 meter of the reactor. 


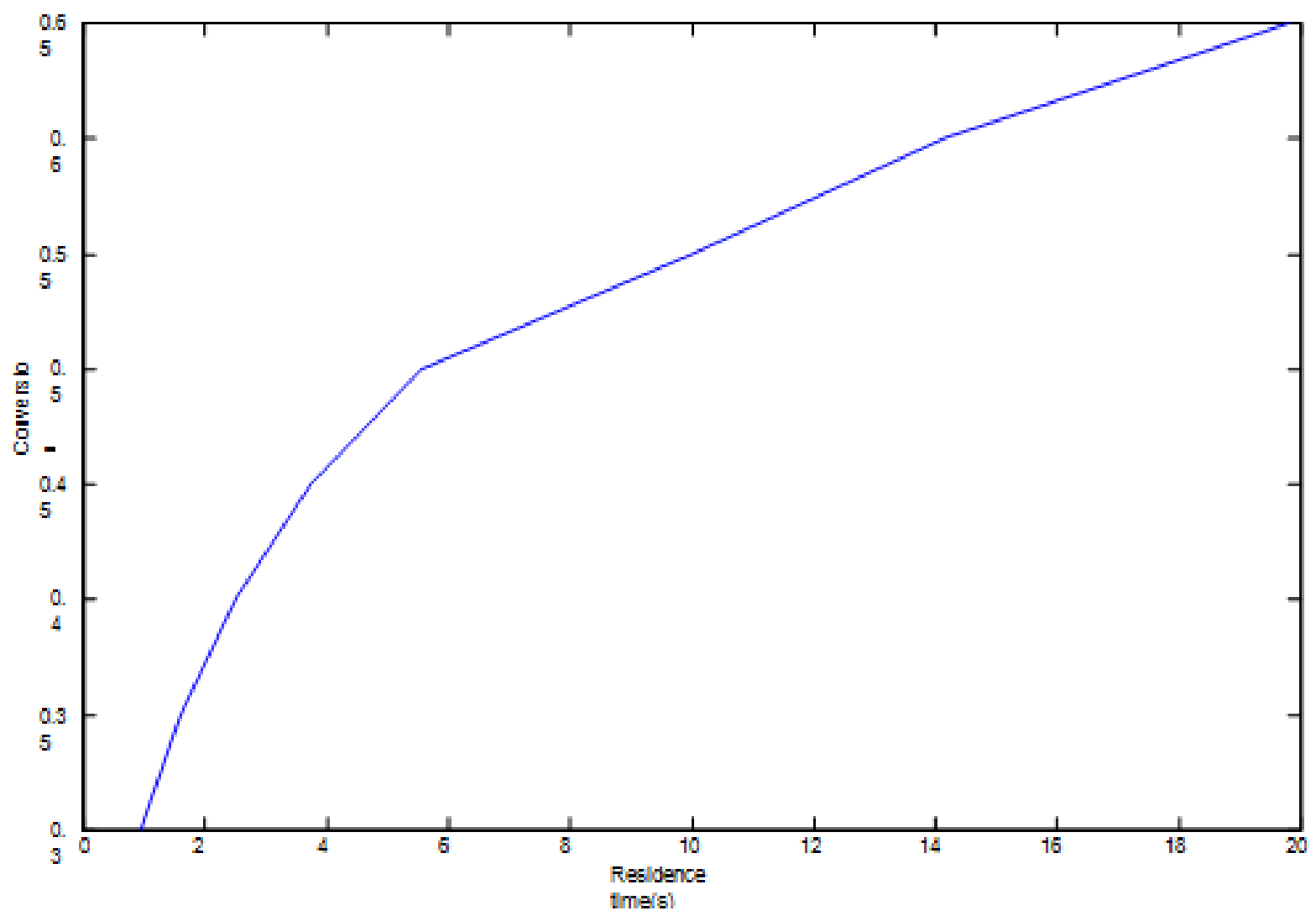

Fig 10: Graph of Conversion against residence time in sec.

From figure 10 above it is evident that conversion increases with residence time and this is what is expected for a plug flow reaction. The residence time for the reaction at $65 \%$ conversion is about 20 seconds.

The main criterion for the furnace reactor design depends on the selection of the proper dimension that provide the lowest value of pressure drop and residence time to prevent any explosion and coking of the hydrocarbons throughout the reactor.

From the plots presented, it is evident that the lowest and stable value for pressure drop is obtainable from figure 8 . Design parameters deduced from model results are compared with actual plant specification as shown in table 2 below:

Table 2: Comparison of model prediction with actual plant specification for design parameters at $65 \%$ conversion

\begin{tabular}{|l|l|l|l|l|}
\hline S/N & Parameter & $\begin{array}{l}\text { Model } \\
\text { prediction }\end{array}$ & $\begin{array}{l}\text { Plant } \\
\text { Specification }\end{array}$ & $\begin{array}{l}\text { Absolute } \\
\text { relative } \\
\text { error (\%) }\end{array}$ \\
\hline 1. & $\begin{array}{l}\text { Tube } \\
\text { diameter d(m) }\end{array}$ & 0.1524 & 0.1600 & 4.75 \\
\hline 2. & $\begin{array}{l}\text { Tube } \\
\text { thickness } \\
\Delta d(m)\end{array}$ & 0.0095 & 0.0100 & 5.00 \\
\hline 3. & $\begin{array}{l}\text { Pressure drop } \\
\Delta p(K p a)\end{array}$ & 0.57 & 0.45 & 21.10 \\
\hline 4. & $\begin{array}{l}\text { Reactor } \\
\text { Temperature, }\end{array}$ & 1461 & 1373 & 6.41 \\
\hline
\end{tabular}

\begin{tabular}{|l|l|l|l|l|}
\hline & $\mathrm{T}_{\mathrm{R}}(\mathrm{k})$ & & & \\
\hline 5. & $\begin{array}{l}\text { Reactor } \\
\text { Length } \mathrm{Z}(\mathrm{m})\end{array}$ & 155.0 & 152.0 & 1.97 \\
\hline 6. & $\begin{array}{l}\text { Residence } \\
\text { time } \tau,(s)\end{array}$ & 19.1780 & 15.20 & 26.17 \\
\hline
\end{tabular}

Where: From table 2, the deviation of model predictions with respect to actual plant design specification represented as absolute relative error, it can be deduced that the accuracy of the design model is sufficient for predicting design specification of a furnace reactor for cracking $100 \%$ ethane feed.

\section{CONCLUSION}

The presented numerical design model of ethane cracking in a furnace reactor is evaluated and found suitable in determining the reactor specification for effective design. An adequate reactor dimension is required to achieve the optimum conversion of the feed. Hence this model was found to be accurate for predicting a $65 \%$ ethane conversion to ethylene for a feed of $100 \%$ ethane.

\section{NOMENCLATURE}

$\mathrm{A}=$ Cross- sectional area of the reactor tube, $\left(\mathrm{m}^{2}\right)$

$\mathrm{C}_{\mathrm{i}}=$ Concentration of species $\mathrm{i},\left(\mathrm{kmol} / \mathrm{m}^{3}\right)$

$\mathrm{C}_{\mathrm{Pi}}=$ Specific heat capacity of component $\mathrm{i},(\mathrm{KJ} / \mathrm{Kmol})$

$\mathrm{d}=$ Pipe internal diameter, $(\mathrm{m})$

$\mathrm{F}_{\mathrm{AO}}=$ Inlet molar fined rate of ethane, $(\mathrm{Kmol} / \mathrm{sec})$

$\mathrm{F}_{\mathrm{i}}=$ Molar flow rate of species $\mathrm{i}$ at any point, $(\mathrm{Kmol} / \mathrm{sec})$ 
$\mathrm{F}_{\mathrm{T}}=$ Total molar flow rate of gas mixture at any point,

$(\mathrm{Kmol} / \mathrm{sec})$

$\mathrm{F}_{\mathrm{TO}}=$ Total inlet molar flow rate $(\mathrm{Kmol} / \mathrm{sec})$

$\mathrm{f}=$ Fanning friction factor

$\mathrm{G}=$ Mass flux, $\left(\mathrm{Kg} / \mathrm{m}^{2} \mathrm{~S}\right)$

$\Delta H_{298}^{\circ}=$ Heat of formation, $(\mathrm{Kg} / \mathrm{Kmol})$

$\Delta H_{R}=$ Heat of pyrolysis reaction, $(\mathrm{KJ} / \mathrm{Kmol})$

$\mathrm{h}_{\mathrm{i}}=$ Heat transfer coefficient of reactor tube inner surface

$\mathrm{K}_{1}=$ Reaction rate constant $\left(\mathrm{S}^{-1}\right)$

$\mathrm{M}_{\mathrm{wt}}=$ Molecular weight of ethane $(\mathrm{Kg} / \mathrm{Kmol})$

$\mathrm{n}_{\mathrm{i}}=$ Number of moles of species $\mathrm{i}$

$\mathrm{P}_{\mathrm{O}}=$ Inlet total Pressure, $(\mathrm{KPa})$

$\mathrm{P}_{\text {Tot }}=$ Total pressure of gas mixture in reactor $(\mathrm{KPa})$

$\mathrm{q}=$ Heat input from furnace (KJ/s-m (of reactor length))

$\mathrm{q}_{\mathrm{c}}=$ Heat input from furnace to convection zone $(\mathrm{KJ} / \mathrm{s}-\mathrm{m})$

$\mathrm{q}_{\mathrm{R}}=$ Heat input from furnace to radiation zone $(\mathrm{KJ} / \mathrm{s}-\mathrm{m})$

$\mathrm{R}=$ Universal gas constant $\left(\mathrm{KPam}^{3} / \mathrm{Kmol}\right)$

$\mathrm{Re}=$ Reynolds number

$\mathrm{r}_{\mathrm{A}}=$ Specific reaction rate $\left(\mathrm{Kmol} / \mathrm{m}^{3} \mathrm{~s}\right)$

$\mathrm{T}_{\mathrm{i}}=$ Inlet feed Temperature, $(\mathrm{K})$

$\mathrm{T}_{\text {out }}=$ Outlet- temperature, $(\mathrm{K})$

$\mathrm{T}_{\mathrm{R}}=$ Absolute reactor temperature, $(\mathrm{K})$

$\mathrm{V}_{\mathrm{R}}=$ Reactor volume,$\left(\mathrm{m}^{3}\right)$

$\mathrm{V}=$ Superficial velocity,$(\mathrm{m} / \mathrm{s})$

$\mathrm{y}_{\mathrm{A}}=$ Mole fraction of ethane

$\mathrm{Z}=$ Length of reactor tube, $(\mathrm{m})$

\section{GREEK SYMBOLS}

$\alpha_{A}=$ Mole fraction of ethane converted to products

$\alpha_{i}=$ range of $0.0-0.65$

$\rho=$ Density of the mixture at any point in the reactor

$\left(\mathrm{Kg} / \mathrm{m}^{3}\right)$

$\tau=$ Residence time, $(\mathrm{S})$

$\mu=$ Viscosity of ethane at inlet condition $(\mathrm{Kg} / \mathrm{ms})$

$\Delta p=$ Pressure drop along the reactor $(\mathrm{KPa})$

\section{REFERENCES}

[1]. Derek, J. Lough [1971]: Computer-model for Reactor Design of an Ethane cracking convective zone unit. Being a M.Sc thesis in chemical engineering.

[2]. Coulson and Richardson[2005]:Chemical Engineering Design Volume 6" $4^{\text {th }}$ ed., Elsevier publications, United Kingdom,

[3.] Kim, D.K. , C.Y. Cha, W.T. Lee, and J.H. Kim [2001]: Microwave Dehydration of Ethane to Ethylene Journal of Industrial Engineering Chemistry, 7(6),

[4]. Rase, H.F [1977]: Chemical Reactor Design for Process Plants, Volume one: Principles and Techniques", John Wiley and Sons, New York.

[5]. Fogler, H.S. [1998]: Elements of Chemical Reaction Engineering", $3^{\text {rd }}$ edition, Prentice Hall, India,

[6]. Smith, J.M. H.C. Van Ness, and M.M. Abbott [1996]:

"Introduction to Chemical Engineering Thermodynamics", $5^{\text {th }}$ ed., McGraw Hill Co.

[7]. Hatch, L.F. and Matar, S. [1981] : From Hydrocarons to Petrochemicals", Gulf Publishing Co.

[8]. McCabe, W.L, Smith, J.C. and Harriort, P[1993]: Unit Operations of Chemical Engineering", $5^{\text {th }}$ ed., McGraw Hill Co.

\section{BIOGRAPHY}

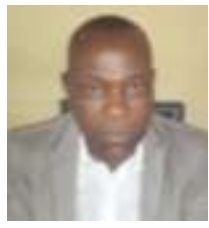

Animia A. Wordu (PhD) was a Senior Process Technologist with many years of industrial experienceith the Port Harcourt Refining Company, Alesa-Eleme, Port Harcourt, Nigeria; before going for his Doctorate degree with the Rivers State University of Science and Technology, Nkpolu, Port Harcourt, Nigeria. After completion of PhD, was retained as a Lecturer with the Department of Chemical/Petrochemical Engineering. His researches are majorly tailored to the Process Industry especially Reactors and Chemical Engineering Thermodynamics. 